\title{
Preclinical discovery of ixabepilone, a highly active antineoplastic agent
}

\author{
Francis Y. F. Lee $\cdot$ Robert Borzilleri \\ Craig R. Fairchild · Amrita Kamath · Richard Smykla • \\ Robert Kramer · Gregory Vite
}

Received: 30 November 2007 / Accepted: 26 February 2008 / Published online: 18 March 2008

(C) Springer-Verlag 2008

\begin{abstract}
The epothilones and their analogs constitute a novel class of antineoplastic agents, produced by the myxobacterium Sorangium cellulosum. These antimicrotubule agents act in a similar manner to taxanes, stabilizing microtubules and resulting in arrested tumor cell division and apoptosis. Unlike taxanes, however, epothilones and their analogs are macrolide antibiotics, with a distinct tubulin binding mode and reduced susceptibility to a range of common tumor resistance mechanisms that limit the effectiveness of taxanes and anthracyclines. While natural epothilones A and B show potent antineoplastic activity in vitro, these effects were not seen in preclinical in vivo models due to their poor metabolic stability and unfavorable pharmacokinetics. A range of epothilone analogs was synthesized, therefore, with the aim of identifying those with more favorable characteristics. Here, we describe the preclinical characterization and selection of ixabepilone, a semi-synthetic epothilone B analog, among many other epothilone analogs. Ixabepilone demonstrated superior preclinical characteristics, including high metabolic stability, low plasma protein binding and low susceptibility to multidrug resistance protein-mediated efflux, all of which were predictive of potent in vivo cell-killing activity. Ixabepilone also demonstrated in vivo antitumor activity in a range of human tumor models, several of which displayed resistance to commonly used agents such as anthracyclines and taxanes.
\end{abstract}

F. Y. F. Lee · R. Borzilleri · C. R. Fairchild · A. Kamath ·

R. Smykla $\cdot$ R. Kramer $\cdot$ G. Vite

Bristol-Myers Squibb Pharmaceutical Research Institute,

Princeton, NJ, USA

F. Y. F. Lee $(\square)$

Bristol-Myers Squibb Co., P.O. Box 4000, K22-03,

Princeton, NJ, USA

e-mail: francis.lee@bms.com
These favorable preclinical characteristics have since translated to the clinic. Ixabepilone has shown promising phase II clinical efficacy and acceptable tolerability in a wide range of cancers, including heavily pretreated and drug-resistant tumors. Based on these results, a randomized phase III trial was conducted in anthracycline-pretreated or resistant and taxane-resistant metastatic breast cancer to evaluate ixabepilone in combination with capecitabine. Ixabepilone combination therapy showed significantly superior progression-free survival and tumor responses over capecitabine alone.

Keywords Antimicrotubule $\cdot \beta$ III-Tubulin - Epothilone · Multidrug resistance $\cdot$ Preclinical

\section{Introduction}

Since the clinical antitumor activity of the taxanes was discovered in the 1990s, the rationale for using microtubulestabilizing agents in the treatment of cancer is undisputed [1]. Taxanes are clinically active against a wide range of tumor types, and play a key role in the treatment of both primary and metastatic breast cancer [2]. However, resistance to cytotoxic drugs (including taxanes) is common, and results in reduced response rates and ultimate disease progression in most patients with metastatic cancer [3]. While some tumors display intrinsic resistance to chemotherapeutic drugs, and thus show no response, others are initially responsive to chemotherapy, but subsequently develop acquired resistance. Both intrinsic and acquired resistance lead to a requirement for alternative treatment options [3].

A major mechanism by which tumors display resistance to commonly used agents such as taxanes and anthracyclines 
is through overexpression of multidrug resistance (MDR) proteins including P-glycoprotein (P-gp) and multidrug resistance-associated protein (MRP)-1 [4]. Overexpression of these efflux pump proteins causes retention of sub-therapeutic concentrations of drug in tumor cells, which results in a lack of efficacy. In some tumors that are intrinsically resistant to chemotherapy, expression of MDR proteins reflects the constitutive expression of these proteins by the tissues from which the tumors are derived (for example, liver and kidney). However, in tumors derived from tissue types that do not express MDR proteins physiologically, treatment with chemotherapy can induce expression of these proteins. This results in acquired resistance to the chemotherapy agent used, in addition to drugs of the same class and, on occasion, of different classes [3]. In the case of the taxanes, at least one other mechanism of drug resistance is known to exist: the overexpression of the $\beta$ III-tubulin isoform in preference to the $\beta \mathrm{II}$ isoform reduces the efficacy of taxanes, as these drugs specifically target the $\beta \mathrm{II}$ isoform [5-8].

In recent years, there has been a great deal of interest among the oncology community in targeted agents. It is now widely acknowledged that agents such as trastuzumab (which targets HER2 in breast cancer) and bevacizumab (which targets VEGF to inhibit angiogenesis in a range of solid tumors) have the potential benefits of at least comparable efficacy and reduced side-effects compared with cytotoxic agents. However, targeted therapies are only effective in subsets of patients with tumors expressing the target molecule, hence it is likely that cytotoxic agents will remain important in the treatment of cancer, either in combination with other agents [as seen clinically with paclitaxel in combination with bevacizumab in trials of non-small cell lung carcinoma (NSCLC)] or second-line to other therapies $[9,10]$. There is, therefore, a pressing need for the development of novel antineoplastic agents that are able to overcome major mechanisms of tumor drug resistance.

Natural epothilones and their analogs are a novel class of antineoplastic agents, produced by the myxobacterium Sorangium cellulosum $[11,12]$. Like the taxanes, epothilones promote tumor cell death by stabilizing microtubules and inducing apoptosis [13]. However, as macrolide antibiotics, the epothilones are structurally unrelated to taxanes and have a distinct tubulin-binding mode. Moreover, unlike taxanes and anthracyclines, epothilones have low susceptibility to multiple mechanisms of tumor cell resistance, including MDR, $\beta$ III-tubulin overexpression and $\beta$-tubulin mutations $[8,14,15]$.

The potential for reduced susceptibility to common mechanisms of tumor resistance led to preclinical and clinical evaluation of natural epothilones A-F (Fig. 1a), and a wide range of synthetic and semi-synthetic analogs of these agents. This review will describe the preclinical development and selection of a particular epothilone analog, BMS-247550 (ixabepilone), a semi-synthetic analog of natural epothilone B that has shown phase II clinical activity in a wide range of tumor types, including those heavily pretreated with, and/or resistant to, prior therapies [16-26].

\section{Epothilones and their analogs: a novel class of antineoplastic agents}

Epothilones are 16-member macrolides with unique antibacterial and antifungal activity. Preclinical experiments have shown that natural epothilones A and B have potent antineoplastic activity against a wide range of tumor cell lines in vitro $[14,27]$. This is particularly true for epothilone $\mathrm{B}$, which showed greater in vitro activity when compared with epothilone A [28, 29]. However, this promising in vitro activity of these natural epothilones did not translate into robust in vivo preclinical antitumor efficacy [30]. This was due to the poor metabolic stability and unfavorable pharmacokinetic properties of natural epothilones seen in rodent models. Synthetic and semi-synthetic epothilone analogs were, therefore, developed, with the aim of yielding more favorable preclinical characteristics that would lead to improved in vivo activity $[31,32]$. This was possible due to the fact that epothilones have a structure of only moderate complexity, and are amenable to total and semisynthesis. A range of semisynthetic analogs was developed and tested by Bristol-Myers Squibb in order to identify candidates with a superior efficacy and safety profile versus epothilone B. Of these, ixabepilone is an analog rationally designed for high in vivo efficacy, good metabolic stability, low protein binding and increased water solubility. The lactone oxygen is replaced with nitrogen, resulting in the lactam compound (Fig. 1b). Significantly, this lactam ring is not susceptible to hydrolysis by esterases, conferring metabolic stability on ixabepilone. Because of its improved water solubility, ixabepilone has a reduced requirement in its formulation for the solubilizing agent cremophor, an agent that has been associated with hypersensitivity reaction in patients.

\section{Preclinical evaluation of ixabepilone}

In order to be of clinical value, an epothilone analog must: (1) be efficacious, resulting in clinically meaningful responses at practical concentrations; (2) have an acceptable safety profile; and (3) be readily available through scalable synthesis.

While the in vitro cytotoxicity/activity of the drug may give some indication of how potent the drug will be in vivo, this is not always the case (as seen for natural epothilones B 
Fig. 1 a Structures of natural epothilones A-F and $\mathbf{b}$ the semisynthetic epothilone B analog ixabepilone a

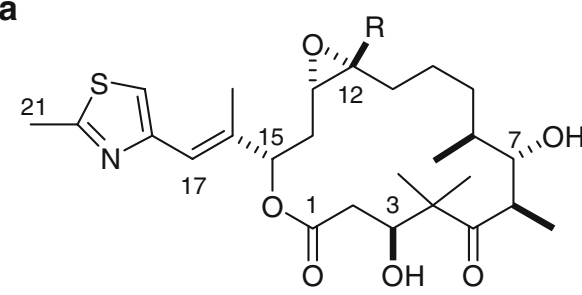

Epothilone $\mathrm{A} \quad \mathrm{R}=\mathrm{H}$<smiles>[R]/C(=C/C[C@H](OC(=O)C[C@H](O)C(C)(C)C(=O)[C@@H](C)[C@@H](O)C(C)CCC/C(C)=C/c1csc(C)n1)C(C)C)CC</smiles>

Epothilone $\mathrm{C} \quad \mathrm{R}=\mathrm{H}$

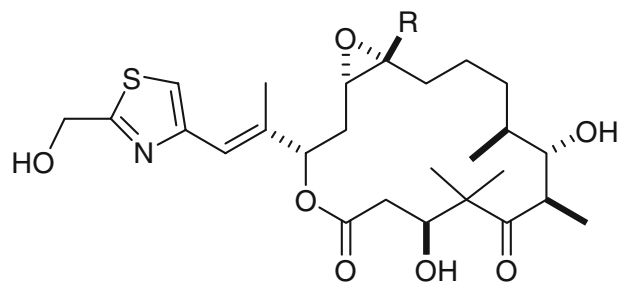

Epothilone $\begin{array}{ll}\mathrm{E} & \mathrm{R}=\mathrm{H} \\ \mathrm{F} & \mathrm{R}=\mathrm{Me}\end{array}$

b

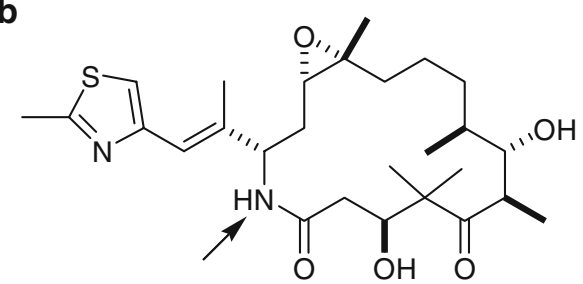

and A). This is because many confounding factors exist in the in vivo environment that are not present in simple in vitro systems, resulting in unpredictable differences in efficacy when a drug initially evaluated in vitro is tested in vivo. For example, even though a drug may have very potent in vitro activity, it will not be clinically effective unless it is metabolically stable in vivo, allowing therapeutic concentrations to be maintained for the required time. Determination of metabolic stability during preclinical development is, therefore, of great importance. Minimal plasma protein binding is another important factor related to in vivo efficacy. If plasma protein binding is too high, effective concentrations of the drug will not be distributed to the target tumor tissues. Due to the clinical significance of MDR in many current chemotherapy treatments, low susceptibility to MDR-mediated efflux is an important characteristic for a novel agent to possess. However, too low a susceptibility to MDR could lead to gastrointestinal toxicity, since gastrointestinal cells normally are protected from the toxic effects of drugs through expression of P-gp. It is important, therefore, that a level of MDR susceptibility of a given drug allows effective drug concentrations to be maintained within cells, while minimizing gastrointestinal toxicity.
In order to evaluate properties that may be predictive of clinical efficacy, a range of preclinical characteristics was determined for 15 semi-synthetic epothilone analogs synthesized by Bristol-Myers Squibb, including ixabepilone. Results of these assays (with brief methodologies) are described below, and summarized in Table 1 .

Preclinical in vivo efficacy

As a measure of antitumor efficacy, log cell kill (LCK) was determined for the 15 epothilone analogs and compared with that for the natural epothilones, using the patientderived Pat-7 ovarian carcinoma model (established from an ovarian cancer patient who had acquired resistance to standard of care chemotherapy, including TAXOL and platinum). Tumor xenografts demonstrated overexpression of P-gp (MDR) and multidrug resistance related protein (MRP) [14]. Tumor fragments approximately $50 \mathrm{mg}$ in size were implanted subcutaneously and animals treated with the natural epothilones or the analogs. Tumor response to treatment was determined as previously described [14]. Statistical evaluations of the data were performed using Gehan's generalized Wilcoxon test [33]. 
Table 1 Preclinical characteristics of natural epothilones and 15 semi-synthetic analogs

\begin{tabular}{|c|c|c|c|c|c|c|c|}
\hline Epothilone/analog & $\begin{array}{l}\text { Analog related } \\
\text { to epothilone }\end{array}$ & $\begin{array}{l}\text { Efficacy } \\
(\mathrm{LCK})\end{array}$ & $\mathrm{IC}_{50}(\mathrm{nM})$ & $\mathrm{EC}_{0.01}(\mu \mathrm{M})$ & $\begin{array}{l}\text { Metabolic stability } \\
{[\mathrm{nmol} /(\mathrm{min} \mathrm{mg})]}\end{array}$ & $\begin{array}{l}\text { Plasma protein } \\
\text { binding }(\%)\end{array}$ & $\begin{array}{l}\mathrm{MDR} \\
\left(\mathrm{IC}_{50} \mathrm{R} / \mathrm{S}\right)\end{array}$ \\
\hline Epothilone A & - & 0.1 & 4.25 & 2.00 & 0.50 & 76.6 & 0.82 \\
\hline Epothilone B & - & 0.4 & 0.41 & 1.80 & 1.02 & 92.0 & 1.48 \\
\hline Epothilone $\mathrm{C}$ & - & ND & 6.30 & 3.65 & 2.40 & ND & ND \\
\hline Epothilone D & - & 0 & 6.00 & 0.60 & 1.20 & 99.9 & 0.98 \\
\hline Epothilone E & - & ND & 6.60 & 15.50 & 0.10 & 90.9 & ND \\
\hline Epothilone F & - & 1.4 & 0.28 & 1.70 & 0.30 & 91.0 & 3.86 \\
\hline BMS-247550 & $\mathrm{B}$ & 2.1 & 2.60 & 2.00 & 0.01 & 79.4 & 7.77 \\
\hline BMS-260807 & $\mathrm{B}$ & 0.3 & 3.40 & 1.50 & 0.20 & 98.0 & 0.88 \\
\hline BMS-264083 & $\mathrm{B}$ & 2.3 & 1.00 & 3.90 & 0.06 & 59.0 & 1.70 \\
\hline BMS-273266 & $\mathrm{B}$ & 0.1 & 0.70 & 2.10 & 0.63 & 99.3 & 0.71 \\
\hline BMS-273645 & A & 0.2 & 2.60 & 1.15 & 1.44 & 92.0 & 0.88 \\
\hline BMS-276026 & $\mathrm{A}$ & 0.8 & 2.70 & 14.1 & 0.26 & 78.6 & 2.52 \\
\hline BMS-298209 & A & 0 & 1.40 & 1.40 & 1.60 & 99.1 & 1.00 \\
\hline BMS-310656 & $\mathrm{B}$ & 0.2 & 4.10 & 2.50 & 0.27 & 89.2 & 1.24 \\
\hline BMS-310704 & $\mathrm{B}$ & 0.4 & 0.29 & 1.00 & 0.27 & 83.8 & 1.50 \\
\hline BMS-310705 & $\mathrm{B}$ & 2.4 & 0.93 & 7.40 & 0.06 & 57.5 & 16.8 \\
\hline BMS-340475 & A & 1.0 & 5.70 & 1.60 & 0.10 & 71.8 & 2.86 \\
\hline BMS-349145 & $\mathrm{D}$ & 0.1 & 130 & 88.9 & 1.75 & 97.0 & 2.45 \\
\hline BMS-357575 & $\mathrm{B}$ & 1.8 & 1.78 & 6.60 & 0.21 & 87.4 & 9.29 \\
\hline BMS-362993 & A & 0.9 & 59.9 & 611 & 0.01 & 89.2 & 3.27 \\
\hline BMS-363008 & $\mathrm{B}$ & 1.6 & 0.94 & 2.10 & 0.58 & 68.4 & 9.11 \\
\hline Efficacy correlation $(r)$ & & & 0.22 & 0.0009 & 0.62 & 0.76 & 0.77 \\
\hline$P$ value (2-tailed)* & & & 0.37 & 0.97 & 0.004 & 0.0002 & 0.0001 \\
\hline
\end{tabular}

$\mathrm{EC}_{0.01}$ : effective concentration, defined as the interpolated concentration of drug capable of inducing an initial tubulin turbidity slope of $0.01 \mathrm{~A} 280$ $\mathrm{nm} / \mathrm{min}$ rate and calculated using the formula $-\mathrm{EC}_{0.01}=$ concentration/slope. Values expressed as means from three different concentrations; $\mathrm{IC}_{50}$ : the concentration of drug required to kill $50 \%$ of HCT-116 tumor cells

$L C K \log$ cell kill; $M D R$ multidrug resistance susceptibility, as determined by the ratio of $\mathrm{IC}_{50}$ values in MDR resistant versus sensitive cell lines (MDR R/S); $N D$ not determined

* Pearson correlation

The LCK for ixabepilone (2.10) was at the upper end of the range obtained for the 15 analogs (0-2.4; Table 1). Furthermore, the LCK for ixabepilone was significantly higher than that for natural epothilone $\mathrm{B}$ ( $\mathrm{LCK}=0.4$; Fig. 2; $P<0.0017)$, suggesting greater in vivo antitumor efficacy for ixabepilone; this was reflected by a more rapid reduction in tumor weight following ixabepilone treatment compared with natural epothilone B.

In vitro evaluations of ixabepilone potency

\section{In vitro cytotoxicity}

Having determined this higher in vivo antitumor activity for ixabepilone versus natural epothilone $B$ and most of the 14 other analogs, in vitro characteristics were compared to determine whether these were predictive of in vivo efficacy. In vitro antitumor potency was assessed on the basis of $\mathrm{IC}_{50}$ values against HCT-116 cells (HCT-116 is a non-P-gp expressing cell line chosen for this purpose in order to avoid susceptibility to MDR as a confounding factor). The $\mathrm{IC}_{50}$ values for the 15 analogs ranged from 0.29 to $130 \mathrm{nM}$. Encouragingly, ixabepilone retained a very low $\mathrm{IC}_{50}$ value $(2.60 \mathrm{nM})$, suggesting high cytotoxicity of this analog. However, the $\mathrm{IC}_{50}$ for ixabepilone was comparable to that of natural epothilone $\mathrm{B}(0.41 \mathrm{nM})$, and the $\mathrm{IC}_{50}$ values did not correlate with in vivo efficacy as measured by LCK (Pearson correlation $r=0.22 ; P=0.37$ ).

\section{Tubulin polymerization}

Although $\mathrm{IC}_{50}$ is a valuable pharmacologic parameter for any drug, the high speed of tubulin polymerization induced by epothilones and their analogs makes the measurement of this end point difficult. The rate of change in the proportion of polymerized tubulin is, therefore, a more accurate 


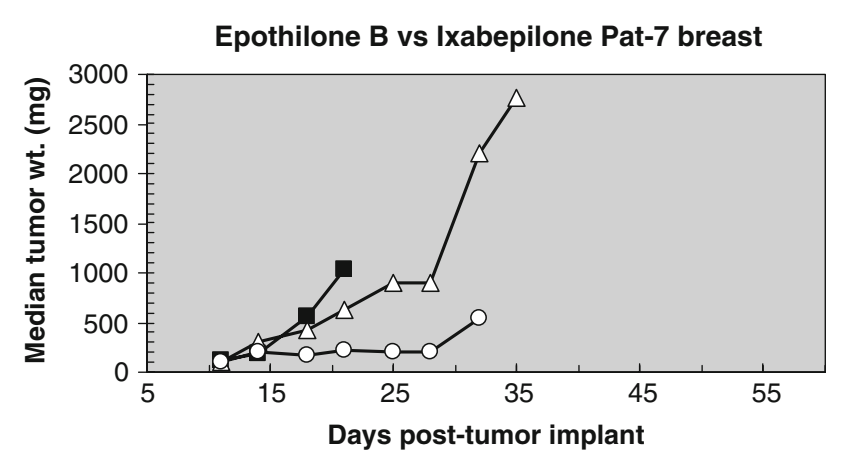

$\rightarrow-$ Control
$\rightarrow-$ Epothilone B $(0.6 \mathrm{mg} / \mathrm{kg}$, q2dx5; 11 ,iv, LCK=0.4)
$\rightarrow-$ Ixabepilone $(3.2 \mathrm{mg} / \mathrm{kg}$, q2dx5;11,iv, LCK = 2.1)

Fig. 2 Median tumor weight against days post-tumor implantation for ixabepilone and epothilone B in the Pat-7 breast carcinoma model

determinant of potency. In order to evaluate tubulinpolymerizing activity, spectrophotometric analyses of turbidity following addition of each drug to a solution of tubulin were performed as previously described [34]. Effective concentration $\left(\mathrm{EC}_{0.01}\right)$ was defined as the interpolated concentration capable of inducing an initial slope of 0.01 A280 $\mathrm{nm} / \mathrm{min}$ rate, and was calculated using the formula: $\mathrm{EC}_{0.01}=$ concentration/slope.

$\mathrm{EC}_{0.01}$ values obtained for the 15 analogs ranged from 1.0 to $611 \mu \mathrm{M}$. Ixabepilone displayed potent tubulin-polymerizing activity, with an $\mathrm{EC}_{0.01}$ value of just $2.0 \mu \mathrm{M}$. This is consistent with the potent cytotoxicity of ixabepilone as demonstrated by its low $\mathrm{IC}_{50}$. However, like $\mathrm{IC}_{50}, \mathrm{EC}_{0.01}$ was not a significant predictor of in vivo efficacy as measured by LCK $(r=0.009 ; P=0.97)$.

Metabolic stability of ixabepilone

As mentioned above, poor metabolic stability of natural epothilone B was one major reason why its promising preclinical antitumor activity did not translate into preclinical in vivo efficacy. Although human plasma does not contain esterases (unlike mouse plasma), esterases in human liver would, nevertheless, be able to degrade epothilones. It was, therefore, important to establish the metabolic stabilities of the natural epothilones and the 15 analogs in order to select those with the greatest stability in mice, particularly in light of the fact that in vitro activity did not appear to be predictive of in vivo activity.

Metabolic stability was assessed by incubating each drug with mouse S9 liver fraction, obtained by standard methods [35] at $37^{\circ} \mathrm{C}$ and sampling at 1,15 , and $45 \mathrm{~min}$. Metabolic stability was expressed as the rate of hydrolysis. The results showed that the metabolic stability of the epothilone analogs tested ranged from 0.01 to $1.75 \mathrm{nmol} /(\mathrm{min} \mathrm{mg}$ protein). Importantly, those analogs susceptible to metabolic breakdown were ineffective in terms of antitumor activity; a Pearson correlation showed that reduced metabolic stability was a significant predictor of poor in vivo antitumor efficacy as measured by LCK (Fig. 3a; $r=0.76 ; P<0.004$ ). Natural epothilones A and B were significantly degraded, with hydrolysis rates of 0.5 and $1.02 \mathrm{nmol} /(\mathrm{min} \mathrm{mg})$, respectively. Ixabepilone, however, showed very high metabolic stability, with a hydrolysis rate of $0.01 \mathrm{nmol} /(\mathrm{min}$ $\mathrm{mg}$ ). Thus, the metabolic stability of ixabepilone was superior to all natural epothilones and analogs tested, with a rate of hydrolysis 100 -fold lower than that of its parent compound, epothilone B. Further nonclinical metabolic studies indicate that ixabepilone is metabolized primarily by cytochrome P450 (CYP) 3A4/5 to many metabolites (but no active metabolites had been identified). Ixabepilone is neither a CYP inhibitor nor a CYP inducer at clinically relevant concentrations (BMS unpublished data).

\section{Plasma protein binding}

Since plasma protein binding is an important determinant of in vivo drug potency (as discussed above) the plasma protein binding characteristics were determined in mouse plasma. Briefly, after determining non-specific binding in blank serum ultrafiltrate, serum samples of test compounds were centrifuged to obtain ultrafiltrates. The percentage protein binding was determined by measuring the concentrations in serum and ultrafiltrate by HPLC-UV assay.

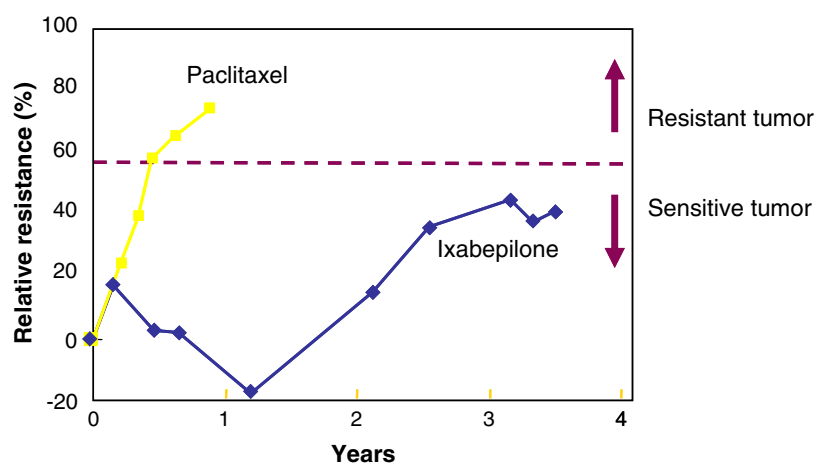

Fig. 3 Development of resistance to paclitaxel, but not ixabepilone, in the human ovarian carcinoma xenograft model A2780. The drug resistance induction protocol employed is as follows: mice bearing the A2780 xenografts were treated with maximum-tolerated dose (MTD) regimens of either paclitaxel $(36 \mathrm{mg} / \mathrm{kg} \mathrm{IV}, \mathrm{Q} 2 \mathrm{D} \times 5)$ or ixabepilone $(10 \mathrm{mg} / \mathrm{kg}, \mathrm{IV}, \mathrm{Q} 4 \mathrm{D} \times 3)$. Treated tumors underwent a typical response pattern of regression followed by regrowth, resulting in tumor responses of 2.4 and 3.5 LCK for paclitaxel and ixabepilone, respectively. A regrown tumor was re-implanted into another group of mice which were then treated again with each drug at their MTDs. This procedure was repeated during the course of over 3 years. For paclitaxel, resistance developed readily with sensitivity decreased by $75 \%$ at the end of 1 year $(\mathrm{LCK}=0.6)$. For ixabepilone, resistance developed more slowly and less completely with responsiveness at $40 \%$ of initial at approximately 3 years $(\mathrm{LCK}=1.4)$ 
Percentage of free compound was expressed as $100 \times$ $\left(C_{\text {filtrate }}\right) /\left(C_{\text {serum }}\right)$. As was the case with low metabolic stability, high plasma protein binding was significantly predictive of poor in vivo efficacy, as measured by LCK (Fig. 3b; $r=0.76 ; P<0.0002)$. Plasma protein binding of the 15 analogs ranged from 57.5 to $99.3 \%$, with natural epothilone B at the upper end of this range, at $92.0 \%$. Importantly, however, the plasma protein binding of ixabepilone was lower than that of natural epothilone $\mathrm{B}$, at 79.4. It should be noted that the degree of binding of the tubulin agents to plasma protein is unrelated to binding potency to the tubulin target itself (e.g. ixabepilone is more potent than paclitaxel in this regard [14], whereas paclitaxel is more plasma protein bound at $96 \%$ ).

\section{Multidrug resistance susceptibility}

Susceptibility to MDR is an important characteristic that is related not only to drug resistance, but also tolerability in the in vivo setting. To establish the susceptibility of each agent to MDR, $\mathrm{IC}_{50}$ values against HCT116/VM46 (MDR resistant) and HCT116 (sensitive) colon cancer cell lines were obtained. The ratio of $\mathrm{IC}_{50}$ values in $\mathrm{MDR}$ resistant versus sensitive lines (MDR R/S) was used as an expression of the relative susceptibility of each drug to MDR; smaller ratios represent lower susceptibility to MDR.

Multidrug resistance R/S ratios for the 15 analogs ranged from 0.88 to 16.8 ; ratios for epothilones $\mathrm{A}$ and $\mathrm{B}$ were 0.82 and 1.48 , respectively. Tolerability was evaluated by using different doses of each analog to determine maximum tolerated dose and weight loss. Not unexpectedly, lower relative MDR susceptibility was a significant predictor of reduced in vivo efficacy, as measured by LCK (Fig. 3c; $r=0.77$; $P<0.0001)$. Notably, of all the measures performed, relative MDR susceptibility was most predictive of in vivo efficacy, suggesting that it is very important to select compounds with a favorable MDR profile if preclinical results are to be translated to the clinic.

The MDR susceptibility ratios were lower with all the epothilone analogs tested compared with the taxanes paclitaxel and docetaxel [14], for which the MDR R/S ratio was $>100$ in a head-to-head comparison. Ixabepilone had an MDR susceptibility ratio of 7.77 , which was substantially lower than that of paclitaxel, but slightly higher than that of most of the other epothilone analogs, thus minimizing the chances of gastrointestinal toxicity.

\section{Further preclinical development of ixabepilone}

The above measures show that ixabepilone has potent in vivo antitumor efficacy, robust metabolic stability, low (but not completely absent) susceptibility to MDR, potent tubulin-polymerizing activity and low plasma protein binding. Since three of these features were found to be significant predictors of in vivo efficacy in mice as measured by LCK, the profile of ixabepilone described above was encouraging. On this basis, ixabepilone was selected from all of the analogs tested for further development. Therefore, a number of additional in vitro and in vivo evaluations were conducted for this agent.

In these additional studies, ixabepilone was found to have high preclinical antineoplastic activity in a range of tumor cell lines and in vivo xenografts $[14,36]$. In agreement with the data presented here, the in vitro activity of ixabepilone matched that of natural epothilone B in terms of cytotoxicity and microtubule-polymerizing ability. Moreover, the in vivo activity of ixabepilone was superior to that of epothilone $\mathrm{B}$, likely due to the higher metabolic stability and lower protein binding of ixabepilone, as described above. Importantly, this in vitro and in vivo activity extended to cell lines and xenograft models displaying acquired resistance to currently available drugs $[14,36]$, consistent with the favorable MDR profile of ixabepilone in the above experiments. Further evaluation of ixabepilone revealed that, whereas taxanes induce apoptosis through upregulation of caspase-9 activity [37], ixabepilone affects multiple apoptotic pathways [38]. Ixabepilone results in enhancement of caspase-2 activity [37] and causes tumor suppressor protein p53 to activate the death effector Bax through induction of expression of the BH3-only protein PUMA [4, 39, 40]. Additionally, a transcription-independent pathway may be involved in Bax activation in response to ixabepilone [41].

\section{Overcoming drug resistance with ixabepilone}

As described above, drug resistance (either intrinsic or acquired) limits the use of cancer chemotherapies such as taxanes and anthracyclines [15]; in such cases, other treatment options must be found if disease progression is to be prevented. In the case of ixabepilone, therapeutic concentrations of drug are theoretically maintained within tumor cells due to the reduced susceptibility of ixabepilone to MDR-mediated efflux [15]. Moreover, ixabepilone does not readily induce tumor cells to overexpress P-gp or MRP-1 [15], suggesting that therapy with ixabepilone would not lead to development of resistance to other drug classes. Indeed, passage of the human ovarian carcinoma xenograft A2780 for more than 3 years in the presence of ixabepilone has not resulted in emergence of resistance. In contrast, resistance to paclitaxel had developed in this model within $<6$ months of continuous paclitaxel exposure (Fig. 3).

In addition to MDR, expression of $\beta$ III-tubulin is associated with clinical resistance to taxanes [5-8]. However, the 
tubulin-binding mode of ixabepilone affects the microtubule dynamics of multiple $\beta$-tubulin isoforms, including $\beta$ IIItubulin [8]. Unlike paclitaxel, which does not target $\beta$ III-tubulin containing microtubules, ixabepilone preferentially suppresses dynamic instability of $\beta$ III-tubulin containing microtubules compared with $\beta$ II-tubulin containing microtubules. Preclinical data also suggest that ixabepilone has activity in models resistant to paclitaxel due to expression of mutant $\beta$-tubulins [14, 42].

Collectively, these preclinical results suggest that ixabepilone may be clinically active against disease which is already resistant to a number of prior therapies. As such, ixabepilone may represent an important potential therapy for cancer patients who have limited treatment options.

\section{Ixabepilone clinical development and future directions}

Following its preclinical assessment and selection for further development, ixabepilone has been evaluated in a large number of clinical trials and has demonstrated promising activity in a broad range of tumor types, including breast cancer, NSCLC, hormone-refractory prostate cancer, renal cancer, advanced pancreatic cancer and relapsed nonHodgkin's lymphoma [16-26]. Particularly striking activity had been observed in metastatic breast cancer (MBC) both in the first-line setting and in patients who were refractory to or had developed resistance to multiple classes of standard chemotherapeutic agents, including importantly taxanes (paclitaxel or docetaxel), anthracyclins and capecitabine (Table 2). These promising activities were confirmed in a randomized, multinational, phase III study in 752 patients with metastatic breast cancer that was resistant to and had progressed after prior anthracyclins and taxane therapy [43]. Based on the results of these pivotal trials (Table 2), the US Food and Drug Administration (FDA) approved ixabepilone for injection (Ixempra ${ }^{\mathrm{TM}}$ ) for the treatment of two breast cancer indications: (1) in combination with capecitabine for the treatment of patients with metastatic or locally advanced breast cancer resistant to treatment with an anthracycline and a taxane, or whose cancer is taxane resistant and for whom further anthracycline therapy is contraindicated. (2) As monotherapy for the treatment of metastatic or locally advanced breast cancer in patients whose tumors are resistant or refractory to anthracyclines, taxanes, and capecitabine.

As mentioned above, efficacy of ixabepilone has also been demonstrated in chemoresistant renal [17, 44] and pancreatic carcinomas [24] and drug-resistant lung cancer [45]. Moreover, clinical trials in breast cancer patients have demonstrated that ixabepilone shows comparable activity in patients with ER- PR- HER2-negative (triple-negative) tumors [46], a disease subgroup with a poor prognosis due to the unsuitability of targeted treatment options (such as hormonal therapies and trastuzumab) [47]. In all cases, ixabepilone had an acceptable and manageable safety profile. Sensory neuropathy, a common side-effect associated with many current antineoplastics including taxanes, did occur with ixabepilone treatment, but in most cases was mild-to-moderate and generally reversible.

Given that synergy between the targeted agent trastuzumab and a number of chemotherapy agents (such as cisplatin, docetaxel, thiotepa and etoposide) have been demonstrated [48-50], it would be a very welcome advance in chemotherapy to demonstrate synergy of targeted agents with antineoplastic agents with lower susceptibility to

Table 2 Ixabepilone clinical development program in breast cancer

\begin{tabular}{|c|c|c|c|c|c|}
\hline Trial type & Disease, characteristics & Dose and schedule & $\begin{array}{l}\text { Number } \\
\text { of patients }\end{array}$ & $\begin{array}{l}\text { Response } \\
(\%)^{\mathrm{a}}\end{array}$ & Publication \\
\hline \multicolumn{6}{|l|}{ Breast } \\
\hline Phase II & $\mathrm{MBC}$, first line & $6 \mathrm{mg} / \mathrm{m}^{2} \mathrm{IV}$ QD $\times 5$ & 23 & 57 & Denduluri et al. [54] \\
\hline Phase II & MBC, resistant to anthracyclines & $40 \mathrm{mg} / \mathrm{m}^{2} \mathrm{IV}$ Q $21 \mathrm{D}$ & 65 & 41.5 & Roche et al. [25] \\
\hline Phase II & $\mathrm{MBC}$, resistant to taxanes & $40 \mathrm{mg} / \mathrm{m}^{2} \mathrm{IV}$ Q $21 \mathrm{D}$ & 49 & 12 & Thomas et al. [55] \\
\hline Phase II & Invasive $\mathrm{BC}$, neoadjuvant & $40 \mathrm{mg} / \mathrm{m}^{2} \mathrm{IV}$ Q $21 \mathrm{D}$ & 164 & $21 \% \mathrm{pCR}$ & Llombart et al. [56] \\
\hline Phase II & $\begin{array}{l}\text { MBC, resistant to anthracyclines, } \\
\text { taxanes, and capecitabine }\end{array}$ & $40 \mathrm{mg} / \mathrm{m}^{2} \mathrm{IV}$ Q $21 \mathrm{D}$ & 126 & 18.3 & Perez et al. [57] \\
\hline \multirow[t]{2}{*}{ Phase III } & \multirow[t]{2}{*}{$\begin{array}{l}\text { MBC, anthracycline, } \\
\text { taxane resistant }\end{array}$} & $\begin{array}{l}\text { Ixabepilone-40 mg/m² IV Q } 21 \mathrm{D} \\
\text { + Capecitabine-2,000 mg/(m² day) PO D1-14 }\end{array}$ & 375 & 35 & \multirow[t]{2}{*}{ Thomas et al. [43] } \\
\hline & & Capecitabine-2,500 mg/(m² day) PO D1-14 & 377 & 14 & \\
\hline \multirow[t]{2}{*}{ Phase III } & \multirow[t]{2}{*}{$\begin{array}{l}\text { MBC, anthracycline, } \\
\text { taxane resistant }\end{array}$} & $\begin{array}{l}\text { Ixabepilone-40 mg/m } / \mathrm{m}^{2} \mathrm{IV} \text { Q } 21 \mathrm{D} \\
\text { + Capecitabine-2,000 mg/(m² day) PO D1-14 }\end{array}$ & $\sim 1,200$ & NA & \multirow[t]{2}{*}{ Not yet published } \\
\hline & & Capecitabine-2,500 mg/(m² day) PO D1-14 & & NA & \\
\hline
\end{tabular}

${ }^{\text {a }}$ ORR (overall response rate), unless otherwise stated, pCR, pathological complete response 
Table 3 Status of clinical development of other epothilones and epothilone analogs

\begin{tabular}{|c|c|c|c|}
\hline Epothilone/epothilone analog & Clinical trial results & Toxicities profiles & References \\
\hline $\begin{array}{l}\text { Epothilone B (EPO-906; } \\
\text { patupilone) }\end{array}$ & $\begin{array}{l}\text { Phase II: activity seen in breast, lung, } \\
\text { prostate, ovarian and renal cancers } \\
\text { Phase III trials ongoing }\end{array}$ & $\begin{array}{l}\text { Diarrhea (DLT), fatigue, } \\
\text { nausea, vomiting }\end{array}$ & {$[58-61]$} \\
\hline Epothilone D (KOS-862) & $\begin{array}{l}\text { Phase II: activity seen in metastatic breast } \\
\text { cancer pretreated with or progressing } \\
\text { after treatment with anthracycline and taxane }\end{array}$ & $\begin{array}{l}\text { Neuropathy (DLT), impaired } \\
\text { gait and cognitive/perceptual } \\
\text { abnormalities (DLT), chest pain } \\
\text { (DLT), fatigue, nausea and vomiting }\end{array}$ & {$[62,63]$} \\
\hline $\begin{array}{l}\text { ZK-EPO (third generation } \\
\text { synthetic epothilone B analog) }\end{array}$ & $\begin{array}{l}\text { Phase I: activity seen in solid tumors, } \\
\text { including taxane-pretreated breast cancer } \\
\text { Phase II: activity in platinum-resistant } \\
\text { ovarian cancer }\end{array}$ & $\begin{array}{l}\text { Neuropathy, nausea and ataxia } \\
\text { DLT unknown }\end{array}$ & {$[64,65]$} \\
\hline KOS-1584 (epothilone D analog) & $\begin{array}{l}\text { Phase I: disease stabilization in a range } \\
\text { of advanced solid malignancies, } \\
\text { and one partial response seen } \\
\text { in non-small cell lung cancer }\end{array}$ & $\begin{array}{l}\text { Fatigue, diarrhea, fatigue and anorexia } \\
\text { DLT unknown }\end{array}$ & {$[66,67]$} \\
\hline $\begin{array}{l}\text { ABJ879 (C20-desmethyl-C20- } \\
\text { methylsulfanyl-epothilone B) }\end{array}$ & Currently in Phase I development & Unknown & $\begin{array}{l}\text { Results yet } \\
\text { to be published }\end{array}$ \\
\hline
\end{tabular}

$D L T$ dose-limiting toxicity

common tumor resistance mechanisms. Trials are ongoing and planned, therefore, to investigate the efficacy of ixabepilone in combination with targeted agents, such as trastuzumab [51] and bevacizumab, following promising preclinical results [52, 53]. Additionally, pilot studies in mice suggest that although ixabepilone is very sensitive to $\mathrm{pH}$, its oral administration in a buffering solution results in comparable efficacy to that seen with intravenous administration.

A number of other epothilones are currently in clinical development; a brief overview of these studies is provided in Table 3.

\section{Conclusions}

The epothilones are a promising new class of antineoplastic agents that have the ability to overcome a variety of tumor resistance mechanisms, a limiting factor with currently used chemotherapeutic agents. Ixabepilone, an epothilone B analog, was selected for further development from among other epothilone analogs due to its promising spectrum of preclinical characteristics and predictors of clinical efficacy. Ixabepilone has demonstrated efficacy and tolerability across a spectrum of tumor types, including difficult to treat patients with extremely limited treatment options. Ixabepilone also has the potential for clinically significant activity in combination with a range of other agents, such as trastuzumab and bevacizumab. The process of rational design and selection of ixabepilone has led to efficacy and safety in the clinical setting, including promising efficacy in patients with multidrug-resistant disease.

\section{References}

1. Jordan MA (2002) Mechanism of action of antitumor drugs that interact with microtubules and tubulin. Curr Med Chem Anticancer Agents 2:1-17

2. Crown J, O'Leary M, Ooi W (2004) Docetaxel and paclitaxel in the treatment of breast cancer: a review of clinical experience. Oncologist 9:24-32

3. Longley D, Johnston P (2005) Molecular mechanisms of drug resistance. J Pathol 205:275-292

4. Leonessa F, Clarke R (2003) ATP binding cassette transporters and drug resistance in breast cancer. Endocr Relat Cancer 10:4373

5. Ranganathan S, Benetatos C, Colarusso P, Dexter D, Hudes G (1998) Altered beta-tubulin isotype expression in paclitaxel-resistant human prostate carcinoma cells. Br J Cancer 77:562-566

6. Kamath K, Wilson L, Cabral F, Jordan MA (2005) Beta III-tubulin induces paclitaxel resistance in association with reduced effects on microtubule dynamic instability. J Biol Chem 280:12902-12907

7. Mozzetti S, Ferlini C, Concolino P, Filippetti F, Raspaglio G, Prislei S, Gallo D, Martinelli E, Ranelletti FO, Ferrandina G, Scambia $\mathrm{G}$ (2005) Class III \{beta\}-tubulin overexpression is a prominent mechanism of paclitaxel resistance in ovarian cancer patients. Clin Cancer Res 11:298-305

8. Jordan M, Miller H, Ni L, Castenada S, Inigo I, Kan D, Lewin A, Ryseck R, Kramer R, Wilson L, Lee FY (2006) The Pat-21 breast cancer model derived from a patient with primary Taxol ${ }^{\circledR}$ resistance recapitulates the phenotype of its origin, has altered betatubulin expression and is sensitive to ixabepilone. In: Proceedings of american association cancer research 97th annual meeting: LB-280

9. Sandler A, Gray R, Perry MC, Brahmer J, Schiller JH, Dowlati A, Lilenbaum R, Johnson DH (2006) Paclitaxel-carboplatin alone or with bevacizumab for non-small-cell lung cancer. N Engl J Med 355:2542-2550

10. Miller K, Wang M, Gralow J, Dickler M, Cobleigh M, Perez EA, Shenkier T, Cella D, Davidson NE (2007) Paclitaxel plus bevacizumab versus paclitaxel alone for metastatic breast cancer. N Engl J Med 357:2666-2676 
11. Höfle G, Bedorf N, Gerth K, Reichenbach H (1993) Inventors; GBF. Epothilone, deren Herstellungsverfahren sowie diese Verbindungen enthaltende Mittel. German patent 4138042. October 14, 1993. World patent application 9310121. 19 November 1992

12. Gerth K, Bedorf N, Hofle G, Irschik H, Reichenbach H (1996) Epothilones A and B: antifungal and cytotoxic compounds from Sorangium cellulosum (Myxobacteria). Production, physicochemical and biological properties. J Antibiot (Tokyo) 49:560563

13. Bode CJ, Gupta ML, Reiff EA, Suprenant KA, Georg GI, Himes RH (2002) Epothilone and paclitaxel: unexpected differences in promoting the assembly and stabilization of yeast microtubules. Biochemistry 41:3870-3874

14. Lee FYF, Borzilleri R, Fairchild CR, Kim S-H, Long BH, Raventoz-Suarez C, Vite GD, Rose WC, Kramer RA (2001) BMS247550: a novel epothilone analog with a mode of action similar to paclitaxel but possessing superior antitumor activity. Clin Cancer Res 7:1429-1437

15. Wartmann M, Altmann KH (2002) The biology and medicinal chemistry of epothilones. Curr Med Chem Anticancer Agents 2:123-148

16. Baselga J, Gianni L, Llombart A, Manikhas G, Kubista E, Steger G (2005) Predicting response to ixabepilone: genomics study in patients receiving single agent ixabepilone as neoadjuvant treatment for breast cancer (BC). Breast Cancer Res Treat 94:S31 (Abstract 305)

17. Fojo A, Menefee M, Poruchynsky M, Edgerly M, Mickley L, Li N, Tapia E, Merino M, Balis F, Bates S (2005) A translational study of ixabepilone (BMS-247550) in renal cell cancer (RCC): assessment of its activity and demonstration of target engagement in tumor cells. J Clin Oncol 23:388S (Abstract 4541)

18. Galsky MD, Small EJ, Oh WK, Chen I, Smith DC, Colevas AD, Martone L, Curley T, DeLaCruz A, Scher HI, Kelly WK (2005) Multi-institutional randomized phase ii trial of the epothilone B analog ixabepilone (BMS-247550) with or without estramustine phosphate in patients with progressive castrate metastatic prostate cancer. J Clin Oncol 23:1439-1446

19. Hussain M, Tangen CM, Lara PN Jr, Vaishampayan UN, Petrylak DP, Colevas AD, Sakr WA, Crawford ED (2005) Ixabepilone (epothilone B analogue BMS-247550) is active in chemotherapynaive patients with hormone-refractory prostate cancer: a southwest oncology group trial S0111. J Clin Oncol 23:8724-8729

20. Low JA, Wedam SB, Lee JJ, Berman AW, Brufsky A, Yang SX, Poruchynsky MS, Steinberg SM, Mannan N, Fojo T, Swain SM (2005) Phase II clinical trial of ixabepilone (BMS-247550), an epothilone B analog, in metastatic and locally advanced breast cancer. J Clin Oncol 23:2726-2734

21. O'Connor O, Straus D, Moskowitz C, Hamlin P, Portlock C, Gerecitano J, Neylon E, Colevas D, Zelenetz A (2005) Targeting the microtubule apparatus in indolent and mantle cell lymphoma with the novel epothilone analog BMS 247550 induces major and durable remissions in very drug resistant disease. J Clin Oncol 23:16S (Abstract 6569)

22. Smith SM, Pro B, Besien Kv, Conner K, Karrison T, Wong S, Stiff P, Vokes E (2005) A phase II study of epothilone B analog BMS247550 (NSC 710428) in patients with relapsed aggressive nonHodgkin's lymphomas. J Clin Oncol 23:16S (Abstract 6625)

23. Conte P, Thomas E, Martin M, Klimovsky J, Tabernero J (2006) Phase II study of ixabepilone in patients (pts) with taxane-resistant metastatic breast cancer (MBC): final report. J Clin Oncol 24:18S (Abstract 10505)

24. Whitehead RP, McCoy S, Rivkin SE, Gross HM, Conrad ME, Doolittle GC, Wolff RA, Goodwin JW, Dakhil SR, Abbruzzese JL (2006) A phase II trial of epothilone B analogue BMS-247550 (NSC \#710428) ixabepilone, in patients with advanced pancreas cancer: a southwest oncology group study. Invest New Drugs 24:512-520

25. Roche H, Yelle L, Cognetti F, Mauriac L, Bunnell C, Sparano J, Kerbrat P, Delord J-P, Vahdat L, Peck R, Lebwohl D, Ezzeddine $\mathrm{R}$, Cure H (2007) Phase II clinical trial of ixabepilone (BMS247550), an epothilone B analog, as first-line therapy in patients with metastatic breast cancer previously treated with anthracycline chemotherapy. J Clin Oncol 25:3415-3420

26. Zhuang SH, Hung YE, Hung L, Robey RW, Sackett DL, Linehan WM, Bates SE, Fojo T, Poruchynsky MS (2007) Evidence for microtubule target engagement in tumors of patients receiving ixabepilone. Clin Cancer Res 13:7480-7486

27. Bollag DM, McQueney PA, Zhu J, Hensens O, Koupal L, Liesch J, Goetz M, Lazarides E, Woods CM (1995) Epothilones, a new class of microtubule-stabilizing agents with a Taxol-like mechanism of action. Cancer Res 55:2325-2333

28. Kowalski RJ, Giannakakou P, Hamel E (1997) Activities of the microtubule-stabilizing agents epothilones $\mathrm{A}$ and $\mathrm{B}$ with purified tubulin and in cells resistant to paclitaxel $\left(\right.$ Taxol $\left.^{\circledR}\right)$. J Biol Chem 272:2534-2541

29. Altmann K-H (2003) Epothilone B and its analogs - a new family of anticancer agents. Mini Rev Med Chem 3:149-158

30. Lee FYF, Vite G, Borzilleri RM, Arico MA, Clark JL, Fager KL, Kan D, Kennedy KA, Kim AS-H, Smykla RA, Wen M-L, Kramer RA (2000) Preclinical pharmacology of the epothilone B analog BMS-247550 — an epothilone analog possessing potent activity against paclitaxel sensitive and resistant human tumors. Clin Cancer Res 6(Supplement):4580s

31. Borzilleri R, Zheng X-P, Schmidt RJ, Johnson JA, Kim S-H, DiMarco JD, Fairchild CR, Gougoutas JZ, Lee FYF, Long B, Vite G (2000) A novel application of a $\mathrm{Pd}(\mathrm{O})$-catalyzed nucleophilic substitution reaction to the regio- and stereoselective synthesis of lactam analogues of the epothilone natural products. J Am Chem Soc 122:8890-8897

32. Johnson J, Kim S, Bifano M, DiMarco J, Fairchild C, Gougoutas J, Lee F, Long B, Tokarski J, Vite G (2000) Synthesis, structure proof, and biological activity of epothilone cyclopropanes. Org Lett 2:1537-1540

33. Gehan EA (1965) A generalized Wilcoxon test for comparing arbitrarily singly-censored samples. Biometrika 52:203-223

34. Swindell CS, Krauss NE, Horwitz SB, Ringel I (1991) Biologically active taxol analogues with deleted A-ring side chain substituents and variable C-2' configuration. J Med Chem 34:1176-1184

35. Raucy J, Lasker J (1991) Isolation of P450 enzymes from human liver. Methods Enzymol 206:577-587

36. Lee FYF, Smykla R, Castaneda S, Johnston K, Kan D, Menard K, McGlinchey K, Peterson RW, Wiebesiek A, Vite G, Fairchild CR, Kramer R (2008) Preclinical efficacy spectrum and pharmacokinetics of ixabepilone. Cancer Chemother Pharmacol (in press)

37. Rojas-Espaillat LA, Uyar D, Grabowski D, Belinson JL, Lee F, Canetta R, Bukowski R, Ganapathi M, Ganapathi R (2005) Apoptotic pathways induced by ixabepilone in paclitaxel-refractory ovarian carcinoma cells. Proc Am Assoc Cancer Res 46 (Abstract 5318)

38. Yamaguchi H, Chen J, Bhalla K, Wang H-G (2004) Regulation of bax activation and apoptotic response to microtubule-damaging agents by 553 transcription-dependent and -independent pathways. J Biol Chem 279:39431-39437

39. Trock BJ, Leonessa F, Clarke R (1997) Multidrug resistance in breast cancer: a meta-analysis of MDR1/gp170 expression and its possible functional significance. J Natl Cancer Inst 89:917-931

40. Larkin A, O'Driscoll L, Kennedy S, Purcell R, Moran E, Crown J, Parkinson M, Clynes M (2004) Investigation of MRP-1 protein and MDR-1 P-glycoprotein expression in invasive breast cancer: a prognostic study. Int J Cancer 112:286-294 
41. Burger H, Foekens JA, Look MP, Meijer-van Gelder ME, Klijn JGM, Wiemer EAC, Stoter G, Nooter K (2003) RNA expression of breast cancer resistance protein, lung resistance-related protein, multidrug resistance-associated proteins 1 and 2, and multidrug resistance gene 1 in breast cancer: correlation with chemotherapeutic response. Clin Cancer Res 9:827-836

42. Giannakakou P, Sackett D, Fojo T (2000) Tubulin/microtubules: still a promising target for new chemotherapeutic agents. J Natl Cancer Inst 92:182-183

43. Thomas ES, Gomez HL, Li RK, Chung H-C, Fein LE, Chan VF, Jassem J, Pivot XB, Klimovsky JV, de Mendoza FH, Xu B, Campone M, Lerzo GL, Peck RA, Mukhopadhyay P, Vahdat LT, Roche HH (2007) Ixabepilone plus capecitabine for metastatic breast cancer progressing after anthracycline and taxane treatment. J Clin Oncol 25:5210-5217

44. Zhuang SH, Menefee M, Kotz H, Agrawal M, Poruchynsky M, Hung E, Zhan Z, Linehan WM, Bates SE, Fojo T (2004) A phase II clinical trial of BMS-247550 (ixabepilone), a microtubule-stabilizing agent in renal cell cancer. J Clin Oncol 22:14S (Abstract 4550)

45. Vansteenkiste J, Lara PN Jr, Le Chevalier T, Breton J-L, Bonomi P, Sandler AB, Socinski MA, Delbaldo C, McHenry B, Lebwohl D, Peck R, Edelman M (2007) Phase II clinical trial of the epothilone $\mathrm{B}$ analog, ixabepilone, in patients with non-small-cell lung cancer whose tumors have failed first-line platinum-based chemotherapy. J Clin Oncol 25:3448-3455

46. Roché H, Perez E, Llombart-Cussac A, Pivot X, Thomas E, Baselga J, Gianni L, Poulart V, Peck R, Martin M (2006) Ixabepilone, an epothilone analog, is effective in ER-, PR-, HER2-negative (triple-negative) patients: data from neoadjuvant and metastatic breast cancer trials. Ann Oncol 17:ix93-113 (Abstract 256-P)

47. Carey L, Dees E, Sawyer L, Gatti L, Moore D, Collichio F, Ollila D, Sartor C, Graham M, Perou C (2004) The triple negative paradox: primary tumor chemosensitivity of the basal-like breast cancer (BBC) phenotype. Breast Cancer Res Treat 88(Suppl 1):S48 (Abstract 1023)

48. Pegram M, Slamon D (1999) Combination therapy with trastuzumab (Herceptin) and cisplatin for chemoresistant metastatic breast cancer: evidence for receptor-enhanced chemosensitivity. Semin Oncol 26(4 Suppl 12):89-95

49. Pegram M, Lopez A, Konecny G, Slamon D (2000) Trastuzumab and chemotherapeutics: drug interactions and synergies. Semin Oncol 27(6 Suppl 11):21-25

50. Burris H 3rd (2001) Docetaxel (Taxotere) in HER-2-positive patients and in combination with trastuzumab (Herceptin). Semin Oncol 27(2 Suppl 3):19-23

51. Moulder S, Wang M, Gradishar W, Perez E, Sparano J, Pins M, Sledge G (2007) A phase II trial of trastuzumab, weekly ixabepilone (BMS-247550) and carboplatin (TIC) in patients with HER2/ neu-positive (HER2+) metastatic breast cancer (BMC): a trial coordinated by the Eastern cooperative oncology group (E2103). Breast Cancer Res Treat 106:S270 (Abstract 6070)

52. Lee FY, Castaneda S, Inigo I, Kan D, Paul B, Wen M-L, Fairchild C, Clark E, Lee H (2005) Ixabepilone (BMS-247550) plus trastuzumab combination chemotherapy induces synergistic antitumor efficacy in HER 2 dependent breast cancers and is accompanied by modulation of molecular response markers. J Clin Oncol 23:16S (Abstract 561)

53. Lee FY, Castenada S, Hawken D, Hickey C, Kan D, Lewin A, Mei-Li Wen, Ryseck R, Fargnoli J, Kramer R (2005) Bevacizumab/ixabepilone (BMS-247550) combination produces synergistic antitumor efficacy in multiple tumor models in vivo and is superior to bevacizumab/paclitaxel combination. In: AACR-NCIEORTC international conference on molecular targets and cancer therapeutics, Philadelphia, PA, p 190 (Abstract B246)
54. Denduluri N, Low JA, Lee JJ, Berman AW, Walshe JM, Vatas U, Chow CK, Steinberg SM, Yang SX, Swain SM (2007) Phase II trial of ixabepilone, an epothilone B analog, in patients with metastatic breast cancer previously untreated with taxanes. J Clin Oncol 25:3421-3427

55. Thomas E, Tabernero J, Fornier M, Conte P, Fumoleau P, Lluch A, Vahdat LT, Bunnell CA, Burris HA, Viens P, Baselga J, Rivera E, Guarneri V, Poulart V, Klimovsky J, Lebwohl D, Martin M (2007) Phase II clinical trial of ixabepilone (BMS-247550), an epothilone B analog, in patients with taxane-resistant metastatic breast cancer. J Clin Oncol 25:3399-3406

56. Cussac AL, Baselga J, Manikhas G, Kubista E, Steger G, Galbraith SM, Sullivan MA, Zerba K, Lee H, Gianni L (2005) Phase II genomics study in patients receiving Ixabepilone as neoadjuvant treatment for breastcancer (BC): preliminary efficacy and safety data. J Clin Oncol 23:16S (Abstract 586)

57. Perez EA, Lerzo G, Pivot X, Thomas E, Vahdat L, Bosserman L, Viens P, Cai C, Mullaney B, Peck R, Hortobagyi GN (2007) Efficacy and safety of ixabepilone (BMS-247550) in a phase II study of patients with advanced breast cancer resistant to an anthracycline, a taxane, and capecitabine. J Clin Oncol 25:3407-3414

58. Thompson J, Swerdloff J, Escudier B, Dutcher J, Bukowski R, Vaishampayan U, Hussain A, Negrier S, Rothermel J (2003) Phase II trial evaluating the safety and efficacy of EPO906 in patients with advanced renal cancer. Proc Am Soc Clin Oncol 22:405 (Abstract 1628)

59. Osterlind K, Sanchez JM, Zatloukal P, Hamm J, Belani CP, Kim E, Felip E, Johri A, Berton M, Sklenar I (2005) Phase I/II dose escalation trial of patupilone every 3 weeks in patients with nonsmall cell lung cancer. J Clin Oncol 23:16S (Abstract 7110)

60. Rubin EH, Rothermel J, Tesfaye F, Chen T, Hubert M, Ho Y-Y, Hsu C-H, Oza AM (2005) Phase I dose-finding study of weekly single-agent patupilone in patients with advanced solid tumors. J Clin Oncol 23:9120-9129

61. Smit WM, Sufliarsky J, Spanik S, Wagnerova M, Kaye S, Oza AM, Gore M, Williams K, Johri A, Ten Bokkel Huinink WW (2005) Phase I/II dose-escalation trial of patupilone every 3 weeks in patients with relapsed/refractory ovarian cancer. J Clin Oncol 23:16S (Abstract 5056)

62. Buzdar A SP, Kaufman PA, Waintraub S, Doyle T, Kroener J (2005) A phase II study of KOS-862 (epothilone D) in anthracycline and taxane pretreated metastatic breast cancer: updated results. Breast Cancer Res Treat 94(Suppl 1):S69 (Abstract 1087)

63. Overmoyer B, Waintraub S, Kaufman PA, Doyle T, Moore H, Modiano M, Kroener J, Zhang X, Buzdar A, Demario M (2005) Phase II trial of KOS-862 (epothilone D) in anthracycline and taxane pretreated metastatic breast cancer. J Clin Oncol 23:16S (Abstract 778)

64. Schmid P, Kiewe P, Kuehnhardt D, Korfel A, Lindemann S, Giurescu M, Reif S, Thiel E, Possinger K (2005) A phase I study of the novel, third generation epothilone ZK-EPO in patients with advanced solid tumors. J Clin Oncol 23:16S (Abstract 2051)

65. Rustin GJ, Reed NS, Jayson G, Ledermann JA, Adams M, Stredder C, Wagner A, Giurescu M, The ZKEPOSGiP-ROC (2007) Phase II trial of the novel epothilone ZK-EPO in patients with platinum resistant ovarian cancer. J Clin Oncol 25:18S (Abstract 5527)

66. Villalona-Calero M, Goel S, Schaaf L, McCracken B, Desai K, Cropp G, Zhou Y, Johnson R, Hannah A, Mani S (2006) First-inhuman phase I trial of a novel epothilone, KOS-1584. J Clin Oncol 24:18S (Abstract 2003)

67. Stopeck A, Moulder S, Jones S, Cohen J, McDowell M, Cropp G, Zhong Z, Wells S, Hannah A, Burris H (2007) Phase I trial of KOS-1584 (a novel epothilone) using two weekly dosing schedules. J Clin Oncol 25:18S (Abstract 2571) 